\title{
Dysplasia in inflammatory bowel diseases: Definition and clinical impact
}

\author{
Karel Geboes PhD MD ${ }^{1}$, Paul Rutgeerts PhD MD ${ }^{2}$
}

K Geboes, P Rutgeerts. Dysplasia in inflammatory bowel disease: Definition and clinical impact. Can J Gastroenterol $1999 ; 13(8): 671-678$. Dysplasia is a morphological term that ethymologically means 'malformation'. For the definition of inflammatory bowel disease-related dysplasia, the nature and origin of the malformation are stressed and the lesion is defined as an epithelial malformation that is unequivocally neoplastic but noninvasive. The use of a precise definition is necessary because of the clinical consequences related to the finding of dysplasia in IBD. The microscopic diagnosis of dysplasia, however, remains difficult. Clinically, it is important to make a proper differential diagnosis between polypoid IBD-related dysplasia and sporadic adenoma occurring in IBD, and between therapy-related 'pseudodysplasia' and genuine dysplasia. When dysplasia is diagnosed, a second opinion may be indicated because of the clinical consequences. Additional techniques to search for genetic defects associated with carcinogenesis can help to support the diagnosis. They can identify changes in DNA content and molecular changes resulting from defects of genes controlling cell proliferation and death or tissue structure. These changes can, however, be absent, appear early or late in the transition from normality toward dysplasia and cancer, or appear during repair. Positive findings indicate an increased cancer risk, but the magnitude of the risk remains to be defined. A positive diagnosis of genuine dysplasia necessitates clinical action - either follow-up of the patient or treatment. In practice, treatment means surgery because dysplasia can be a precursor and/or a marker of malignancy, except for sporadic adenomas, which can be removed locally.

Key Words: Dysplasia; Inflammatory bowel disease

\section{La dysplasie dans les maladies inflammatoires de l'intestin : définition et impact clinique}

RÉSUMÉ : Le terme dysplasie est un terme morphologique qui étymologiquement signifie « malformation ». Pour ce qui est de la définition de la dysplasie liée aux maladies inflammatoires de l'intestin (MII), on insiste sur la nature et l'origine de la malformation et la lésion est définie comme une malformation épithéliale qui est, sans équivoque, néoplasique mais non invasive. L'emploi d'une définition précise est nécessaire à cause des conséquences cliniques liées à la découverte d'une dysplasie dans une MII. Cependant, le diagnostic microscopique d'une dysplasie reste difficile. Cliniquement, il est important de poser un diagnostic différentiel correct entre la dysplasie de polypes liée à une MII et un adénome sporadique survenant dans la MII, et entre la «pseudodysplasie » liée à un traitement et la dysplasie authentique. Le diagnostic d'une dysplasie nécessite la demande d'un deuxième avis à cause des conséquences cliniques. Des techniques additionnelles de dépistage de défauts génétiques associés à une carcinogenèse peuvent permettre d'étayer le diagnostic. Ces techniques peuvent identifier des changements dans le contenu de l'ADN et des changements moléculaires résultant de défauts de gènes contrôlant la prolifération et la mort cellulaires ou la structure des tissus. Toutefois, ces changements peuvent être absents, apparaître tôt ou tardivement dans la phase de transition qui va de la normalité vers la dysplasie et le cancer, ou survenir pendant la réparation. Les données positives révèlent un risque de cancer accru, mais l'ampleur du risque reste à être déterminée. Un diagnostic positif de dysplasie authentique nécessite une action clinique soit le suivi du patient ou un traitement. En pratique, traiter signifie opérer puisque la dysplasie peut être un précurseur ou un marqueur de malignité, sauf dans le cas d'adénomes sporadiques qui peuvent être enlevés par voie locale.
$\mathrm{T}$ he increased risk of malignancy, more specifically of colorectal cancer (CRC), is a major problem in the long term management of patients with chronic inflammatory bowel diseases (IBD). The risk of CRC in longstanding ulcerative colitis (UC) has been particularly in focus since the recognition of this complication in 1928, and management

This mini-review was prepared from a presentation made at the World Congress of Gastroenterology, September 6 to 11, 1998, Vienna, Austria

${ }^{1}$ GI Pathology Unit, ${ }^{2}$ Department of Gastroenterology, University Hospital, KU Leuven, Belgium

Correspondence and reprints: Karel Geboes, Department of Pathology, University Hospital KU Leuven, Minderbroedersstraat 12, 3000 Leuven,

Belgium, Telephone 32-16-33-65-84,fax 32-16-33-65-48, e-mail karel.geboes@uz.kuleuven.ac.be

Received for publication December 1, 1998. Accepted December 10, 1998 
strategies have been controversial ever since (1). Premalignant polypoid changes of the mucosa associated with CRC in UC were recognized in the late 1950s and later described in more detail in flat mucosa as precancerous changes $(2,3)$.

These alterations were later referred to as dysplasia. Looking for dysplasia in endoscopic biopsies has, since then, been used for secondary prevention and in surveillance programs for the early detection of CRC in IBD. However, the practical application and the cost effectiveness of this search are not entirely satisfactory because of problems with inter- and intraobserver variability among pathologists and because of uncertainties in the clinical interpretation of the report resulting from the histopathological assessment of dysplasia. The purpose of the present review is to clarify the definition of dysplasia and to discuss its relation with the molecular genetics associated with carcinogenesis.

\section{DEFINITION OF DYSPLASIA}

'Dysplasia' is a word derived from the ancient Greek language. It is composed of two elements - 'dys' and 'plasis'. 'Dys' means 'bad' or 'wrong' - as in dysphagia, to eat badly, or in dyspepsia, to digest badly. 'Plasis' means 'form', as in plastic arts. The original meaning of dysplasia is thus malformation, or a morphologic structure that is different from what is normally expected. 'Dysplasia' is a term that is commonly used in medicine for various and highly different macroscopic and microscopic lesions, occurring in various organ systems. Fibromuscular arterial dysplasia and dysplasia of the kidney are two examples of the widespread use of this term. The term 'fibromuscular arterial dysplasia', as used in the circulatory system, is an arterial disease, most often occuring in the renal arteries as a reversible cause of renal hypertension and characterized by accumulation of cellular fibrous tissue in the intima (the inner layer of the arteries) obstructing the lumen and inducing ischemia. Dysplasia of the kidney is a congenital condition resulting from a disturbed differentiation of nephrogenic tissue and characterized by the persistence of tissues that are normally only found in the embryo. The use of 'dysplasia' as a terminology for such different lesions is understandable because of its original significance.

When used as such, however, the origin and meaning of the term dysplasia are undefined. The origin of a malformation can indeed be variable. It can be congenital (hereditary or not) or acquired. If acquired, the dysplastic transformation can be regenerative (due to healing and repair following damage) or neoplastic (degenerative). Although the word 'dysplasia' is sometimes used to describe macroscopic lesions, its main use is in histopathology. In general pathology, it is used to describe both epithelial and stromal lesions. It can still mean 'only malformation' or it can be related to neoplasia and malignancy. This double meaning exists also in gastrointestinal pathology, where dysplasia in angiodysplasia, a misnomer for vascular ectasia, or in neuronal dysplasia describes a malformation, either acquired or congenital (4). In both these conditions, dysplasia is used for stromal lesions. When used for alterations of the epithelium lining the gas- trointestinal tract, the meaning of dysplasia is usually entirely different, and it is understood that there is a relation with neoplasia. Yet there are numerous definitions available, even for epithelial lesions of the gastrointestinal tract, and the relation with neoplasia may be either strong or weak.

Dysplasia has been defined as a lesion in which part of the epithelium is replaced by cells showing varying degrees of atypia, or as atypia. The latter definition is, however, usually restricted to the description of cytological abnormalities, while the word 'dysplasia' also encompasses changes in architecture and aberrant differentiation in addition to possible cytological disturbances. The classical and most usual manifestation of gastrointestinal dysplasia, according to this definition, corresponds to a circumscribed, elevated lesion or adenoma (5).

In some textbooks, tissue is considered dysplastic when "the cellular architecture is distorted or deficient" (6). Changes in tissular architecture and the appearance of immature cells (altered differentiation) are, however, phenomena that also occur during repair. Restitution, one of the healing mechanisms occurring in the gastrointestinal tract, is characterized by increased migration of young, immature epithelial cells, covering up superficial defects (7).

The application of a purely morphological definition of dysplasia is, therefore, not always adapted to the possible clinical consequences. In earlier studies of early gastric cancer, dysplasia was also defined as a process of disordered cell growth, as epithelial atypia or alteration, or as excessive abnormal proliferation of the gastric epithelium, microscopically recognized on the basis of cellular atypia, abnormal maturation and a disorganized mucosal architecture. The lesions were subdivided into several categories. Usually a distinction was made between different grades. A variety of experimental investigations and follow-up studies of patients showed that mild degrees of dysplasia, as used in some of these classifications, were clinically irrelevant and largely reactive in nature (8-10).

It is exceedingly difficult to outline properly the clinical consequences and therapeutic attitudes to consider when such a variety of definitions are used. Therefore, a more precise definition of dysplasia has been proposed for lesions observed in patients with IBD. According to this definition, dysplasia is used for lesions showing "unequivocal, noninvasive (confined within the basement membrane), neoplastic transformation of the epithelium excluding all reactive changes". This definition implies that the lesion can be recognised by microscopy (11). The definition stresses the nature and origin of the lesion, but its identification still relies on the recognition of morphological features resulting from cytological and architectural changes in routinely processed and hematoxylin- and eosin-stained sections. The distinction between neoplastic and reactive changes is clinically very important but in practice not always easy. Reactive changes appearing during healing are characterized by increased proliferation and the presence of less differentiated, immature cells, which differ from the normal cells in shape, cytoplasmic staining and nuclear aspect (Figure 1). This may 
render the differential diagnosis with genuine dysplasia difficult. The presence of inflammation rather orients toward reactive changes because it is more commonly found in areas of epithelial damage and, hence, reactive changes. During healing, proliferation as indicated by the presence of mitoses, must remain within the normal proliferative compartment, the location of which is well defined in the gastrointestinal tract. Mitoses occurring in an aberrant location are abnormal. Therefore, although the criteria are defined more precisely, the recognition of dysplasia still depends on observation in routine microscopy and interpretation of the findings. This partly explains the interobserver differences found in various studies $(12,13)$.

When a biopsy is diagnosed as positive for dysplasia, a distinction is made between different grades of severity. The lesions are subdivided into three categories (mild, moderate and severe) or two categories (low grade and high grade) based on the severity of the neoplastic alterations (11). In general, it has been shown that interobserver agreement is better for high grade dysplasia.

When a biopsy is diagnosed as negative for dysplasia, it must be realized that dysplasia in IBD usually has a patchy distribution throughout the colon, leading to problems with sampling error. Even if 20 to 40 biopsies are taken, less than $0.1 \%$ of the colorectal mucosa is sampled (14). Still, accumulated experience from several prospective studies shows that six to 10 different biopsies from different sites are sufficient to detect significant dysplasia (15).

The same definition of dysplasia was later applied to other conditions of the gastrointestinal tract that carry an increased cancer risk, such as Barrett's esophagus, and to the squamous epithelium of the esophagus. The natural history of dysplasia and its relation with carcinogenesis have been studied in these conditions, and these findings can aid in the understanding of what is happening in IBD-related dysplasia.

\section{DIFFERENTIAL DIAGNOSIS}

Overall, the major differential diagnosis when considering dysplasia in a patient with IBD is the differential between genuine dysplasia and reactive lesions, mainly due to repair with or without inflammation. Follow-up studies have shown that there are also a few other special conditions with differential diagnoses that are clinically important. Several studies have looked into the correlation between the endoscopic features of dysplasia associated with IBD and the microscopic diagnosis of dysplasia. In general, it appears that IBD-associated dysplasia can show no macroscopic lesions or can appear as a flat lesion, as sessile-type polyps or as raised plaque-like lesions referred to as dysplasia-associated lesions or masses (DALMs) (16). Surveillance studies have shown that a distinction has to be made between IBD-related dysplasia, especially the polypoid or raised type, and a sporadic adenoma occurring in IBD. While the latter is unequivocally a neoplastic and hence a dysplastic lesion, its development is unrelated to the underlying IBD. The clinical distinction between IBD-associated dysplasia, especially the polypoid dys-

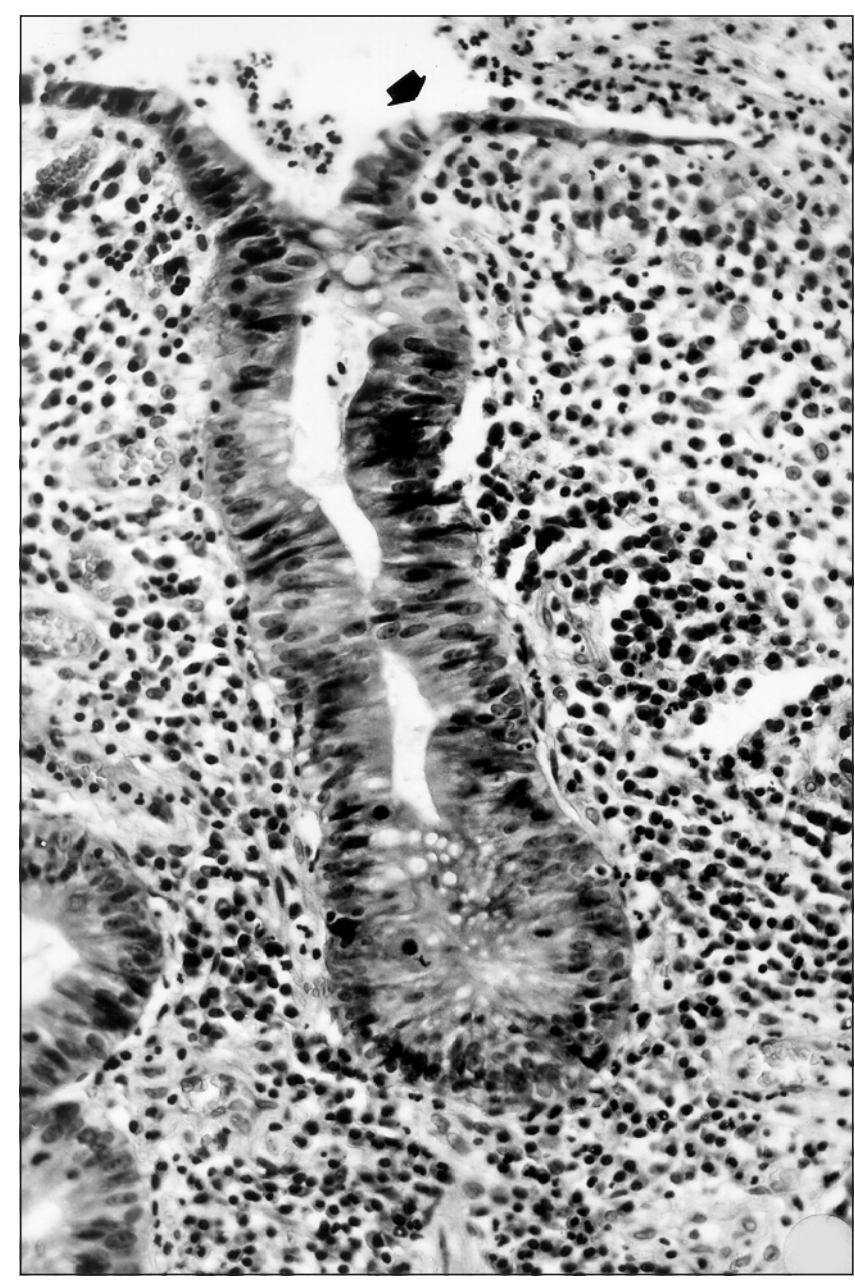

Figure 1) Crohn's disease regenerative lesion. The cells lining the crypt show stratification of the nuclei, but in the upper part of the crypt the cells become more cuboidal and on the surface they have an attenuated aspect where they cover a denuded area (hematoxylin and eosin, magnification $\times 315)$.

plastic lesions, on the one hand, and sporadic adenomas on the other hand, is extremely important because the former occur as a result of IBD, and their presence is an indication for colectomy because of a higher association with cancer, whereas the treatment of sporadic adenomas is simple polypectomy. The differential diagnosis between these two types of neoplastic lesions, which both can occur in IBD, is based on a variety of clinical and pathological features. Sporadic adenomas are more common in older patients having no disease activity and a relatively short disease history; inflammation of the lamina propria is less common. Examination of samples obtained in the mucosa surrounding the elevated lesion can help to exclude a DALM and to confirm the diagnosis of a sporadic polyp. Pedunculated lesions found in a dysplasia-free surrounding mucosa should be handled as in noncolitis patients $(17,18)$.

Since the introduction of the definition of dysplasia as a neoplastic lesion and the development of standard criteria for the diagnosis and grading by the Dysplasia Study Group in 1983, knowledge on IBD has greatly increased and treat- 


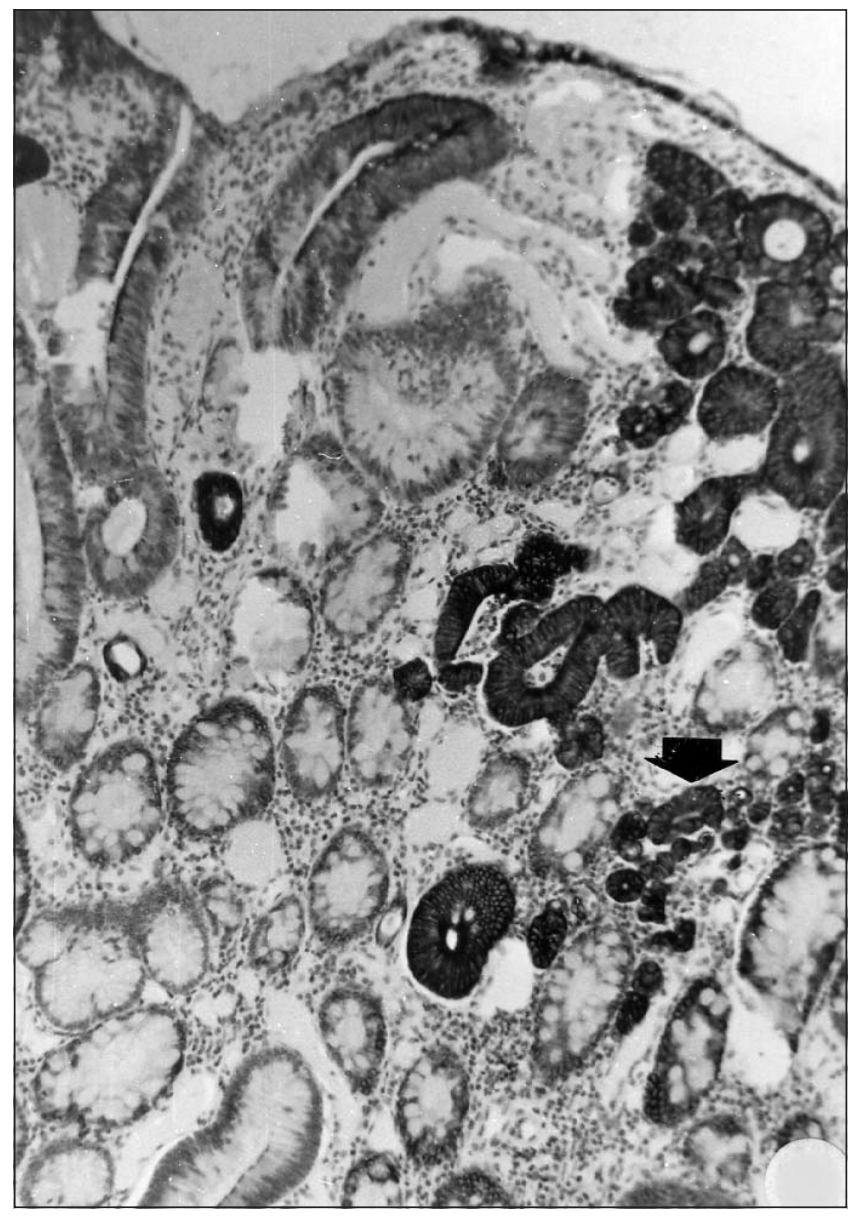

Figure 2) Sporadic tubular adenoma stained with antibodies directed against cytokeratins (clone MNF116, reactive with cytokeratins $5,6,8,17$ and 19) showing a different and clearly positive expression in the area which contains early invasive cancer (immunoperoxydase, magnification $\times 125$ )

ment has become more effective. The development of more effective drugs has had some impact on the diagnosis and differential diagnosis of dysplasia. The newer drugs can reduce inflammatory activity drastically and rapidly, while regeneration takes more time. This discrepancy can result in follow-up biopsies showing little or no inflammatory activity and marked regeneration. The latter represents pseudodysplasia and should not be mistaken for dysplasia (19).

\section{DYSPLASIA AND MOLECULAR GENETICS}

In recent years, knowledge of cancer has greatly increased. Cancer is recognized as a condition associated with defects in the genes controlling cell proliferation and cell death. The multistep nature is better recognized, and different forms of CRC, such as hereditary nonpolyposis CRC and sporadic types, have been indentified more precisely $(20)$.

Genetic alterations associated with cancer or neoplasiarelated lesions that can be detected with more recently introduced techniques include, among others, chromosomal alterations, a change in cellular DN A content (aneuploidy), mutations of different genes and the aberrant expression of proteins or the expression of abnormal proteins. Identifica- tion is achieved with different techniques. Changes in nuclear DNA content, reflecting gross chromosomal alterations, can be identified with flow cytometry. Inactivation of tumour suppressor genes such as $p 53$ can be identified using immunohistochemistry for the detection of the mutant $p 53$ protein expression. Mutations of K-ras oncogenes can be detected using polymerase chain reaction (PCR) techniques or immunohistochemistry. Aberrant cytokeratin expression can be identified using PCR, in situ hybridization and immunohistochemistry (Figure 2). These techniques have been applied to a large variety of cancers, including different types of CRC, such as UC-associated CRC. Interpretation of the results depends partially on the technique used, but some general conclusions can be proposed.

For aneuploidy, a close correlation with the development of dysplasia and carcinoma in IBD has been shown in retrospective and prospective studies $(12,21,22)$. It has further been demonstrated that the presence of DNA aneuploidy is not influenced by inflammation. Its detection may, therefore, be more objective with less interobserver variability than for the assessment of dysplasia. It has also been shown that DNA-aneuploidy is an earlier marker than dysplasia. Yet, aneuploidy alone is neither necessary nor sufficient to cause transition toward malignancy and it might also occur later in the process of colonic carcinogenesis in UC $(23,24)$.

In other words, the changes in DNA content can occur before or after the emergence of the morphological features of dysplasia. This is certainly not surprising because the two phenomena do not necessarily have the same origin or consequences. Comparable results have been found with other markers for neoplastic transformation.

Genetic instability resulting in mutations of the DNA mismatch repair genes, detected as changes in microsatellites (short sequences of nucleotides in the genome), has been described in colitis-associated cancer by using PCR. In UC, abnormalities were detected in $21 \%$ of tumour samples and in $19 \%$ of dysplasia samples. The data show no major differences from those obtained for sporadic CRC (25).

\section{DYSPLASIA AND GENETIC DEFECTS IN THE CONTROL OF CELL PROLIFERATION AND CELL DEATH}

Data regarding the occurrence of mutations of K-ras oncogenes and of the adenomatous polyposis coli (APC) and p53 tumour suppressor genes in IBD have been compared with data obtained in sporadic CRC and familial adenomatous polyposis (FAP). Some studies have demonstrated that mutations of the ras oncogenes are less frequent and occur at a later stage in UC-associated CRC, while they are early events in the neoplastic transformation of the mucosa in sporadic CRC $(26,27)$. Mutation of the APC tumour suppressor gene is observed in UC and CRC, but it is less frequent and seems to be a late event compared with FAP and sporadic CRC (28). Bc12 over-expression is less common than in sporadic cancers.

Inactivation of the tumour suppressor gene $p 53$ by mutation and loss of heterozygosity ( $\mathrm{LOH}$ ) seems to be an early 
event in UC-associated CRC, while it may occur late in hereditary nonpolyposis CRC (Figure 3). Interestingly, $\mathrm{LOH}$ of the $p 53$ gene is often detected in tissue containing aneuploid cell populations, suggesting that aneuploidy precedes $p 53$ $\mathrm{LOH}$ in UC (29). These data indicate that different pathways may lead to the development of cancer, although the differences are probably small.

Morphologically, tumour development follows the adenoma to dysplasia to carcinoma sequence. The genetic alterations also occur in a certain preferred order, but this order is not necessarily always the same, and although the order of mutation can have a critical impact on the morphological behaviour (as with ras and APC mutations, which are associated with increased proliferation) it does not, by necessity, have this impact. In other words, the mutations associated with tumour progression do not necessarily determine the morphological appearance of a lesion. This can partly be explained by the function of the proteins coded for by the oncogenes or suppressor genes. Activation of the ras genes leads to signal transduction, which induces a cascade of events that are thought normally to have a role in proliferation and differentiation. Mutation can lead to continuous signal transduction, even in the absence of an external stimulus, and induce continuous proliferation, resulting in a hyperplastic (increase in cell number) lesion such as an adenoma. The $p 53$ protein is involved in the control of the transit from the G0/G1 phase of the cell cycle to the S1 phase. Cells accumulating at the transition are primed for cell death by apoptosis. This is less reflected in the morphology. This difference in morphological consequences is illustrated by p53 mutations, which seem to be an early event in cancer developing in the squamous esophagus and in Barrett's esophagus as shown by the common expression of mutant p53 in normal squamous epithelium in cancer-bearing esophagi and in metaplastic columnar cells in Barrett's esophagus $(30,31)$. In sporadic CRC, it is a rather late event; hence, expression of the mutant $p 53$ may be negative in sporadic adenomas, while in UC- and Crohn's disease-associated cancer, it may be an early event and thus often present in dysplasia, even in the low grade forms $(29,32)$ (Figures 4,5). In general, it, therefore, appears that the same genetic defect can be expressed before or after the alterations in cell shape and size and, therefore, before or after dysplasia can be recognized by routine morphology. In other words, the genetic defects associated with carcinogenesis related to cell proliferation and cell death, inducing alterations in proliferation, do not necessarily occur at the same moment as dysplasia (also implying alterations in shape and architecture). Neither are they necessarily or constantly present.

\section{DYSPLASIA AND GENETIC DEFECTS}

\section{IN THE CONTROL OF TISSUE STRUCTURE}

Cancer development is associated with defects in genes controlling cell proliferation and cell death but also with defects of other important genes. Aberrant expression of proteins and abnormalities in genes coding for proteins involved in the preservation of cell shape and cohesion such as cy-
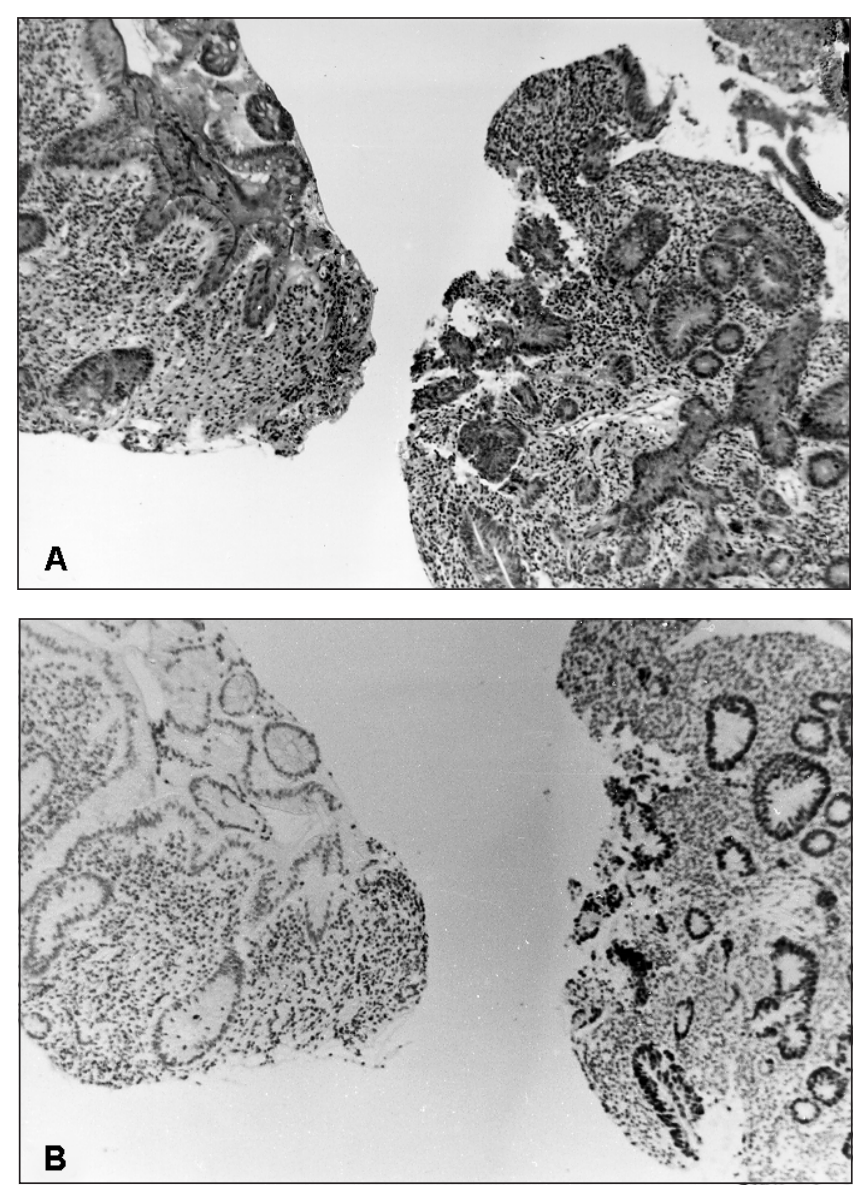

Figure 3) Dysplasia in ulcerative colitis. A Endoscopic colonic biopsies stained with hematoxylin and eosin. Inflammation is prominent in both samples, but the architecture is more disturbed and the epithelial lining shows cytological abnormalities indicative of dysplasia in the sample on the right (hematoxylin and eosin $\times 125$ ). B Serial section stained with antibodies directed against $\mathrm{p} 53$ showing clear nuclear positivity in the sample on the right (immunoperoxydase, magnification $\times 125$ )

tokeratins, CD44 and e-cadherin have been reported in epithelial dysplasia and in many cancers. Cytokeratins are members of a large family of proteins that compose the intermediate filaments in the cytoplasm of most, if not all, epithelial cells. The intermediate filament system and its associated proteins represent a chain of molecular connecting links between the nucleus and the cell surface. They are important for tissue structure and integrity. The e-cadherins are adhesion molecules. They are epithelial proteins that play a key role in the organization and maintenance of the epithelial structure. They mediate cell-cell adhesion. Abnormalities in the structure or loss of these proteins, due to genetic defects, result in changes in cellular shape and size (cytology) and in defects in cell cohesion (architecture). This is illustrated by studies of the squamous esophageal epithelium. Dysplasia of the squamous esophagus is characterized by downregulation of cytokeratin mRNAs, which are specific for the differentiated normal esophageal epithelium and by the upregulation and protein expression of cytokeratin mRNAs and proteins, not present in the normal esophageal epithelium but characteristic of simple epithelia. The 

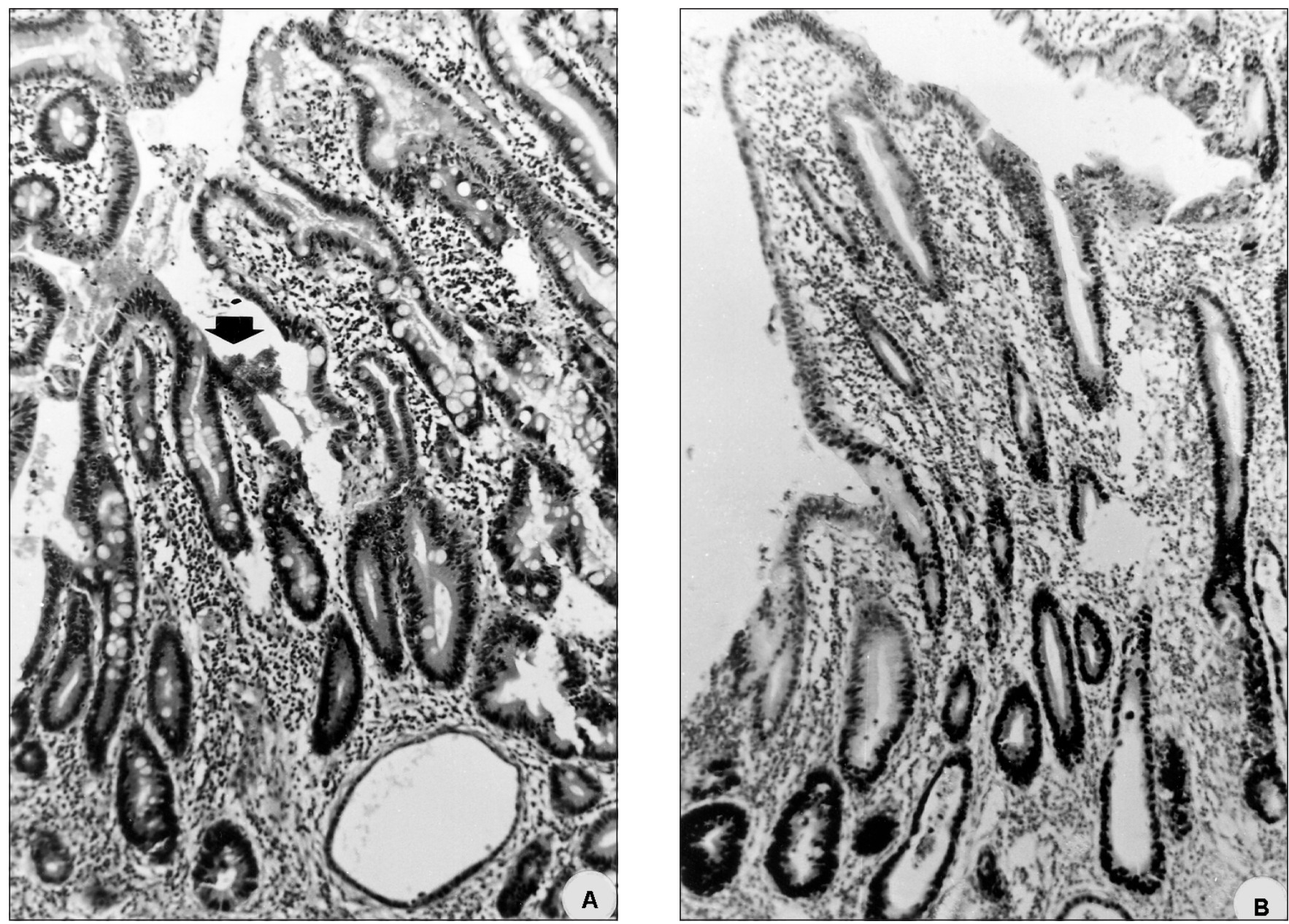

Figure 4) Dysplasia in Crohn's disease. A Small intestinal biopsies with irregular villous architecture. The epithelial cells lining the villi are partially well differentiated. Some crypts show stratification of the nuclei extending towards the surface indicative of dysplasia (hematoxylin and eosin, magnification $\times 125$ ) B Semiserial section stained with antibodies directed against $\mathrm{p} 53$ showing clear nuclear positivity (immunoperoxydase, magnification $\times 125$

normal vertical migration of esophageal cells throughout the epithelium, characteristic for the normal esophagus and illustrated by a sequential expression of different cytokeratin pairs, is completely changed in dysplasia. The changes are more prominent in high grade dysplasia $(33,34)$.

CD44 is a broadly distributed transmembranous glycoprotein acting as a cell adhesion receptor. Its major ligand, hyaluronan, is a common component of the extracellular matrix. Various isoforms of the molecule have been described (35). They show variations in the extracellular part of the molecule, enabling the cells to contact further ligands in addition to or instead of those mentioned above. Expression of the CD44 v6 isoform has been described in colorectal adenomas, simultaneously with changes in the $p 53$ tumour suppressor gene (36). Changes in CD44 isoform expression have been reported in IBD. The investigations were mainly carried out for diagnostic purposes to find markers allowing a differential diagnosis between Crohn's disease and UC (37). This hypothesis has not been confirmed. Instead it has been shown that the proliferation index (\% of positive cells), as assessed using immunohistochemistry and MIB1 as a marker for proliferation, was dramatically increased in CD44 v6-positive crypts in UC and Crohn's disease, compared with v6-negative crypts (38).

Adhesion molecules such as e-cadherins are involved in cell signalling, differentiation and migration, and are related to polarity. Loss of polarity is one of the features used to diagnose dysplasia. Reduced expression of e-cadherin has been reported in UC and Crohn's disease. It was suggested that the changes may be involved in promoting cell migration during epithelial restitution (39). The expression of e-cadherin is also often altered in tumours (40). A selective loss has been noted in poorly differentiated tumours, and it has been suggested that e-cadherin may act as an invasionsuppressor gene. Loss of e-cadherin expression is also found in UC-associated cancers, but there is no difference when the data are compared with those obtained in sporadic cancers (40).

The microscopic features on which a routine diagnosis of dysplasia is based may be related to neoplasia-associated defects in genes in control of proteins involved in the maintenance of cell shape and cohesion, rather than to defects in genes in control of cell proliferation or, more probably, to both. In addition, development of dysplasia may further be 
influenced by growth factor-receptor pairs such as epidermal growth factor and epidermal growth factor receptor.

\section{THE MORPHOLOGICAL DIAGNOSIS OF DYSPLASIA AND THE USE OF ADDITIONAL TECHNIQUES}

A search for genetic alterations to define dysplasia better can offer support for the diagnosis if positive, but a negative finding does not exclude the possibility of dysplasia. Furthermore, the results obtained with additional techniques must be interpreted with caution. Absence or decrease of e-cadherin protein expression occurs in UC-associated CRC and in sporadic CRC. However it is not constantly present in all UC-associated cancers and has been observed also in benign ulcerative lesions in UC $(39,40)$.

Dysplasia and the genetic defects associated with cancer development are different phenomena identified with entirely different techniques. Dysplasia is a complex phenomenon, with multiple factors involved in its development. The search for genetic defects using additional techniques is usually limited to one specific marker. While a combination of routine morphology and new techniques for additional markers can help to identify dysplasia, the search for additional markers itself can only support a diagnosis of dysplasia if positive, or help identify a cancer risk in patients in whom routine morphology fails to detect dysplasia. How important the cancer risk is when aneuploidy is found or when $p 53$ expression is detected remains to be determined.

\section{CLINICAL SIGNIFICANCE OF DYSPLASIA}

While both a positive diagnosis of dysplasia and a positive p53 expression indicate an increased cancer risk, they do not allow the magnitude of the risk to be assessed. Low grade dysplasia itself is the earliest morphologically recognizable form of neoplastic transformation. Its natural history is not precisely known. Yet it may not only be a precursor of cancer. In practice, dysplasia is often already associated with invasive cancer and, hence, is a marker of cancer. This is demonstrated by studies comparing biopsies and subsequently obtained resection specimens $(41,42)$. The difference between the findings on endoscopic biopsy and in a surgical specimen is explained by the sampling problems of endoscopy. The finding of genuine IBD-associated dysplasia, therefore, clearly has clinical implications - either control and regular follow-up of the patient, or treatment, which in practice means surgery.

\section{CONCLUSION}

Dysplasia is a lesion that can be recognized with morphological techniques. To be used properly, the term 'dysplasia' needs to be defined adequately, with regard to both the nature of the lesion and the standard criteria used for its recognition. Dysplasia in IBD is defined as an unequivocally neoplastic but noninvasive lesion. This implies that it is the earliest step in the multistep process of carcinogenesis that can be identified with morphological techniques. Consequently, such a lesion necessitates an appropriate clinical reaction. The clinical consequences depend on the age and

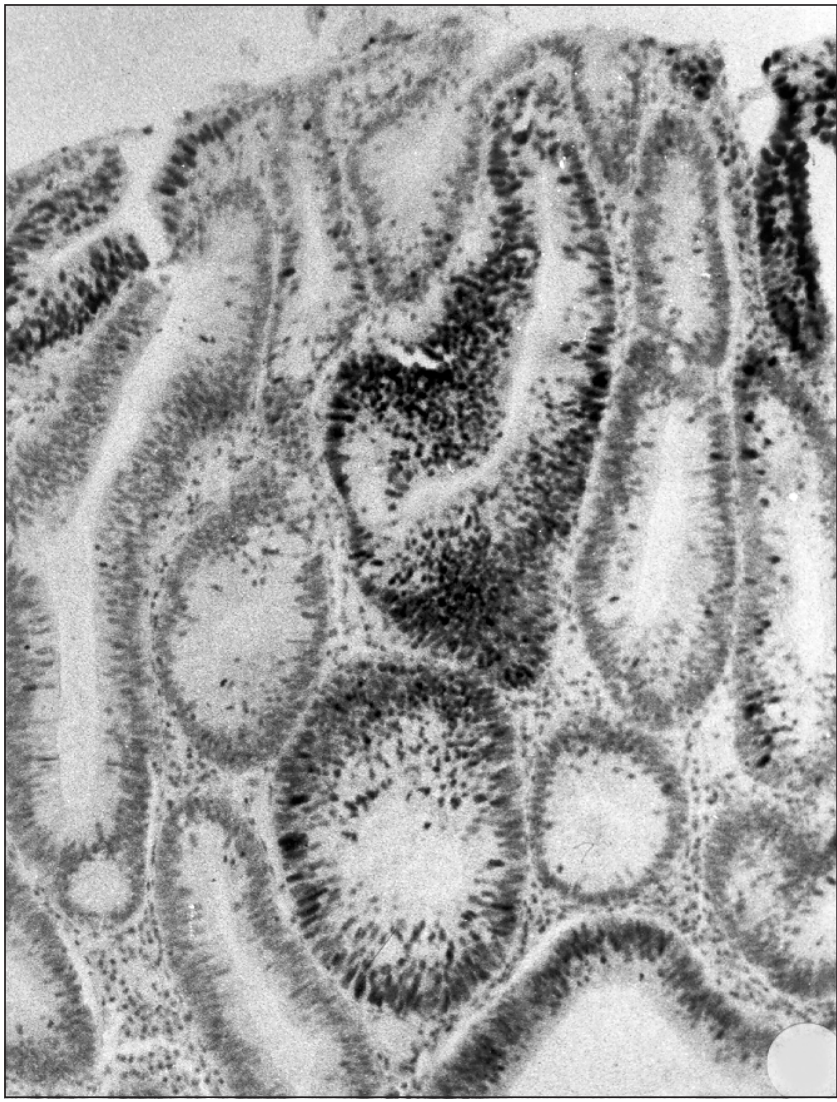

Figure 5) Sporadic adenoma from a noninflammatory bowel disease patient stained with antibodies directed against $\mathrm{p} 53$. Nuclear positivity is present in only a limited part of the neoplastic adenomatous glands and cells (immunoperoxydase, magnification $\times 125$ ).

general condition of the patient and the severity of the dysplastic lesion. A proper diagnosis of dysplasia, especially low grade dysplasia is not always easy and the pathologist must be aware of the consequences of the diagnosis (43). Because of the diagnostic difficulty, in view of the interobserver variations, and given the clinical consequences, a second opinion may be indicated even for low grade dysplasia. The differential diagnosis with pseudodysplasia during treatment and with sporadic adenomas is difficult, but clinically extremely important. The histological evolution of cancer in UC is different from that of sporadic tumours (44). The use of additional techniques can help to solve the problem and can support the diagnosis. Yet aneuploidy and molecular changes due to genetic defects can either be absent or appear early or late in the transition from the normal cell phenotype toward dysplasia and invasive cancer. Because of the possible time difference between the occurrence of genetic defects associated with carcinogenesis and the development of dysplasia, and given the fact that the appropriate techniques measure changes other than dysplasia, the results of both the routine morphology and the special techniques are not always concordant. For these reasons, and because of practical availability and costs, the simple morphological recognition of dysplasia in endoscopic biopsies remains important for the management of the cancer risk in IBD. 


\section{REFERENCES}

1. Bargen JA. Chronic ulcerative colitis associated with malignant disease. Arch Surg 1928;17:561-76.

2. Dawson IMP, Pryse-Davies J. The development of carcinoma in the large intestine in ulcerative colitis. Br J Surg 1959;47:113-28.

3. Morson BC, Pang LSC. Rectal biopsy as an aid to cancer control in ulcerative colitis. Gut 1967;8:423-34

4. Boley S, Brandt LJ. Vascular ectasias of the colon. Dig Dis Sci 1986;31:26S-42S.

5. Jass JR, Sobin LH. Histological Typing of Intestinal Tumours, 2nd edn. Berlin: Springer Verlag, 1989:2-3.

6. Harnden DG, McGee JOD. Neoplasia. In: McGee JOD, Isaacson PG, Wright NA, eds. Oxford Textbook of Pathology, vol 1. Oxford: Oxford University press, 1992:571-89.

7. Henrikson CK, Argenzio RA, Liacos JA, Khosla J. Morphologic and functional effects of bile salt on the porcine colon during injury and repair. Lab Invest 1989;60:72-87.

8. Ming SCH, Bajtai A, Correa P, et al. Gastric dysplasia: significance and pathologic criteria. Cancer 1984;54:1794-1801.

9. Morson BC, Sobin LH, Grundmann E, Johansen A, Nagayo T, Serck-Hanssen A. Precancerous conditions and epithelial dysplasia in the stomach. J Clin Pathol 1980;33:711- 21.

10. Oehlert W, Keller P, Henke M, Strauch M. Die Dysplasien der Magenschleimhaut. Dtsch Med Wochenschr 1975;100:1950-6.

11. Riddel RH, Goldman H, Ransohoff DF, et al. Dysplasia in inflammatory bowel disease: Standardized classification with provisional clinical applications. Hum Pathol 1983;14:931-68.

12. Melville DM, Jass JR, Shepherd NA, et al. Dysplasia and deoxyribonucleic acid aneuploidy in the assessment of precancerous changes in chronic ulcerative colitis. Observer variation and correlations. Gastroenterology 1988;95:668-75.

13. Dobbins WO III. Dysplasia and malignancy in inflammatory bowel disease. Annu Rev Med 1984;35:33-48.

14. Rosenstock E, Farmer RG, Petras R, Sivak MV, Rankin GB, Sullivan BH. Surveillance for colonic carcinoma in ulcerative colitis. Gastroenterology 1985;89:1342-6.

15. Rozen P, Baratz M, Fefer F, Gilat T. Low incidence of significant dysplasia in a successful surveillance program of patients with ulcerative colitis. Gastroenterology 1995;108:1361-70.

16. Blackstone MO, Riddell RH, Rogers BHG, Levin B. Dysplasia associated lesion or mass (DALM) detected by colonoscopy in longstanding ulcerative colitis. An indication for colectomy. Gastroenterology 1981;80:366-74.

17. Torres C, Antonioli D, Odze R. Polypoid dysplasia and adenomas in inflammatory bowel disease. Am J Surg Pathol 1998;22:275-84.

18. Stolte M, Schneider A. Differential diagnosis of adenomas and dysplasias in patients with ulcerative colitis. In: Tytgat GNJ, Bartelsman JFWM, van Deventer SJH, eds. Inflammatory Bowel Diseases. Dordrecht: Kluwer Academic Publishers, 1995:133-44.

19. Hyde GM, Warren BF, Jewell DP. Histological changes following intravenous cyclosporin in the treatment of refractory severe ulcerative colitis may mimic dysplasia. Gut 1998;42:A43. (Abst)

20. Fearon ER, Vogelstein B. A genetic model for colorectal tumorigenesis. Cell 1990;61:759-67.

21. Löfberg R, Broström O, Karlen P, Tribukait B, Öst A. Colonoscopic surveillance in longstanding total ulcerative colitis - a fifteen year follow-up study. Gastroenterology 1990;99:1021-31.

22. Löfberg R, Befrits R, Sjöqvist U, et al. Colorectal cancer in Crohn's disease - high frequency of DNA-aneuploidy. Gut 1996;39:A165. (Abst)

23. Rubin CE, Haggit RC, Burmer C, et al. DNA-aneuploidy in colonic biopsies predicts future development of dysplasia in ulcerative colitis. Gastroenterology 1992;103:1611-20.

24. Karlen P, Löfberg R, Broström O, Tribukait B. Absolute cumulative risk of developing DNA-aneuploidy in longstanding ulcerative colitis. Gastroenterology 1993;104:A720. (Abst)

25. Suzuki H, Harpaz N, Tarmin L, et al. Microsatellite instability in ulcerative colitis-associated colorectal dysplasia and cancers. Cancer Res 1994;54:4841- 4.

26. Burmer GC, Levine DS, Kulander BG, Haggitt RC, Rubin CE, Rabinovitch PS. c-ki-ras mutations in ulcerative colitis and sporadic colon carcinoma. Gastroenterology 1990;99:416-20.

27. Chen J, Compton C, Cheng E, Fromowitz F, Viola MV. c-Ki-ras mutations in dysplastic fields and cancer in ulcerative colitis. Gastroenterology 1992;102:1983-7.

28. Tarmin L, Yin J, Harpaz N, et al. APC gene mutations in ulcerative colitis associated dysplasias and cancers versus sporadic colon neoplasms. Cancer Res 1995;55:2035-8.

29. Burmer GC, Rabinovitch PS, Haggitt RC, et al. Neoplastic progression in ulcerative colitis: Histology, DNA content and loss of p53 allele. Gastroenterology 1992;103:1602-10.

30. Jones DR, Davidson AG, Summers CL, Murray GF, Quinlan DC. Potential application of p53 as an intermediate biomarker in Barrett's esophagus. Ann Thorac Surg 1994;57:598-603.

31. Parenti AR, Rugge M, Frizzera E, et al. p53 overexpression in the multistep process of esophageal carcinogenesis. Am J Surg Pathol 1995; 19:1418-22.

32. Brentnall TA, Crispin DA, Rabinovitch PS, et al. Mutations in the p53 gene: an early marker of neoplastic progression in ulcerative colitis. Gastroenterology 1994;107:369-78.

33. Caulin C, Bauluz C, Gandarillas A, et al. Changes in keratin expression during malignant progression of transformed mouse epidermal keratinocytes. Exp Cell Res 1992;204:11-21.

34. Viaene A, Baert J, Lerut T, Geboes K. In situ hybridisation: a versatile tool to localise gene-expression on tissue sections. Acta Endosc 1997;27:117-27.

35. Geboes K, Rutgeerts P. CD44v6 and CD44v3 variants in inflammatory bowel disease. Lancet 1995;345:1191-2.

36. Mulder JWR, Wielenga VJM, Polak MM, et al. Expression of mutant p53 and CD44 variant proteins in colorectal tumorigenesis. Gut 1995;36:76-80.

37. Rosenberg WMC, Prince C, Kaklamanis L, et al. Increased expression of CD44v6 and CD44v3 in ulcerative colitis but not colonic Crohn's disease. Lancet 1995;345:1205-9.

38. Fromont-Hankard G, Cezard JP, Aigrain Y, Navarro J, Peuchmaur M. CD44 variant expression in inflammatory colonic mucosa is not disease specific but associated with increased cell proliferation. Histopathology 1998;32:317-21.

39. Karagiannakis AJ, Syrigos KN, Efstathion J, et al. Expression of catenins and E-cadherin during epithelial restitution in inflammatory bowel disease. J Pathol 1998;185:413-8.

40. Ilyas M, Tomlinson IP, Hanby A, Talbot IC, Bodmer WF. Allele loss, replication errors and loss of expression of E-cadherin in colorectal cancers. Gut 1997;40:654-9.

41. Hamilton SR. Colorectal carcinoma in patients with Crohn's disease. Gastroenterology 1985;89:398-407.

42. Talbot IC. Dysplasia in the gastrointestinal tract: significance, terminology and diagnosis. Acta Endosc 1996;26:119-24.

43. Foucar E. Do pathologists play dice? Uncertaintly and early histopathological diagnosis of common malignancies. Histopathology 1997;31:495-502.

44. Ilyas M, Tomlinson IPM. Genetic pathways in colorectal cancer. Histopathology 1996;28:389-99. 


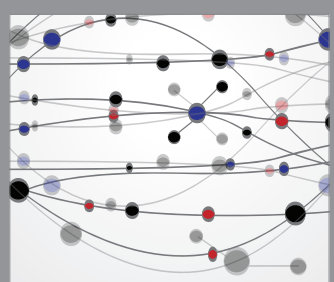

The Scientific World Journal
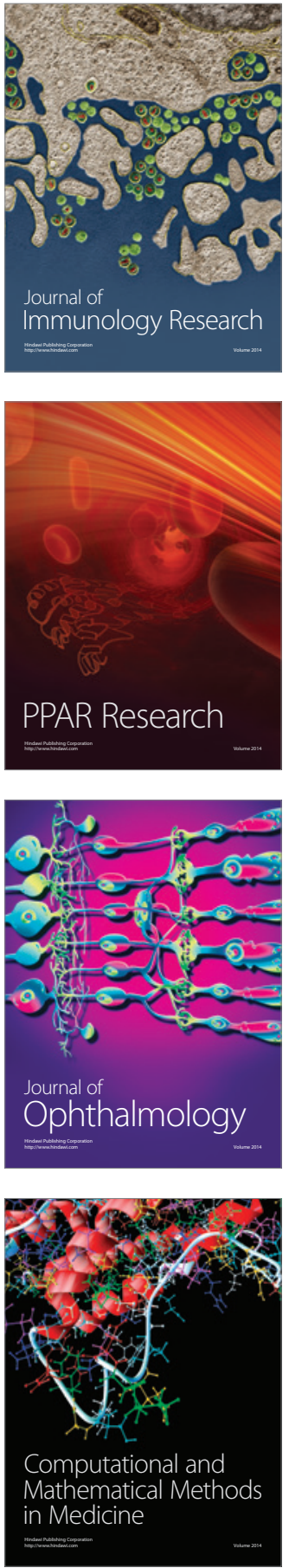

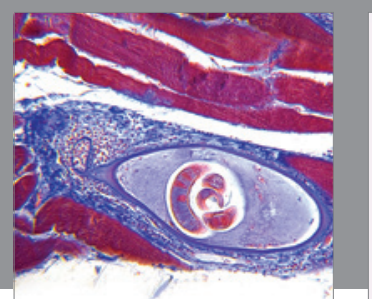

Gastroenterology Research and Practice

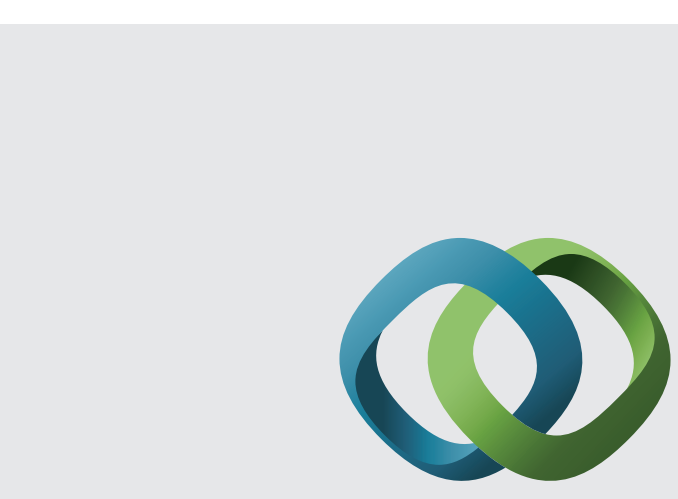

\section{Hindawi}

Submit your manuscripts at

http://www.hindawi.com
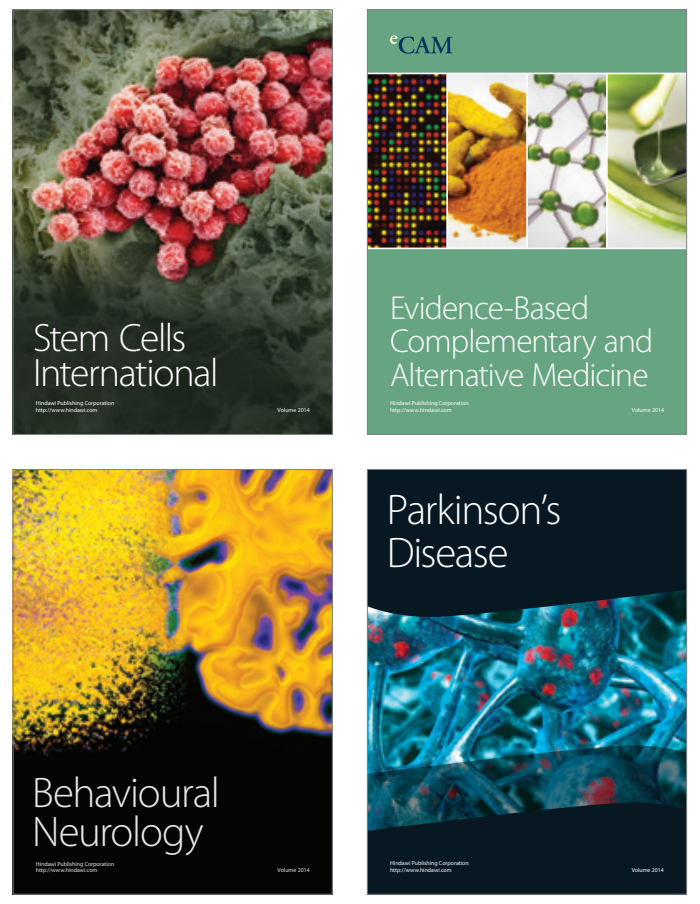
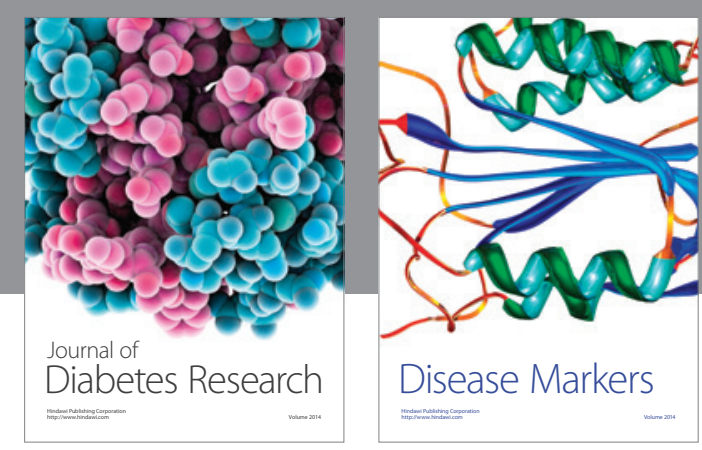

Disease Markers
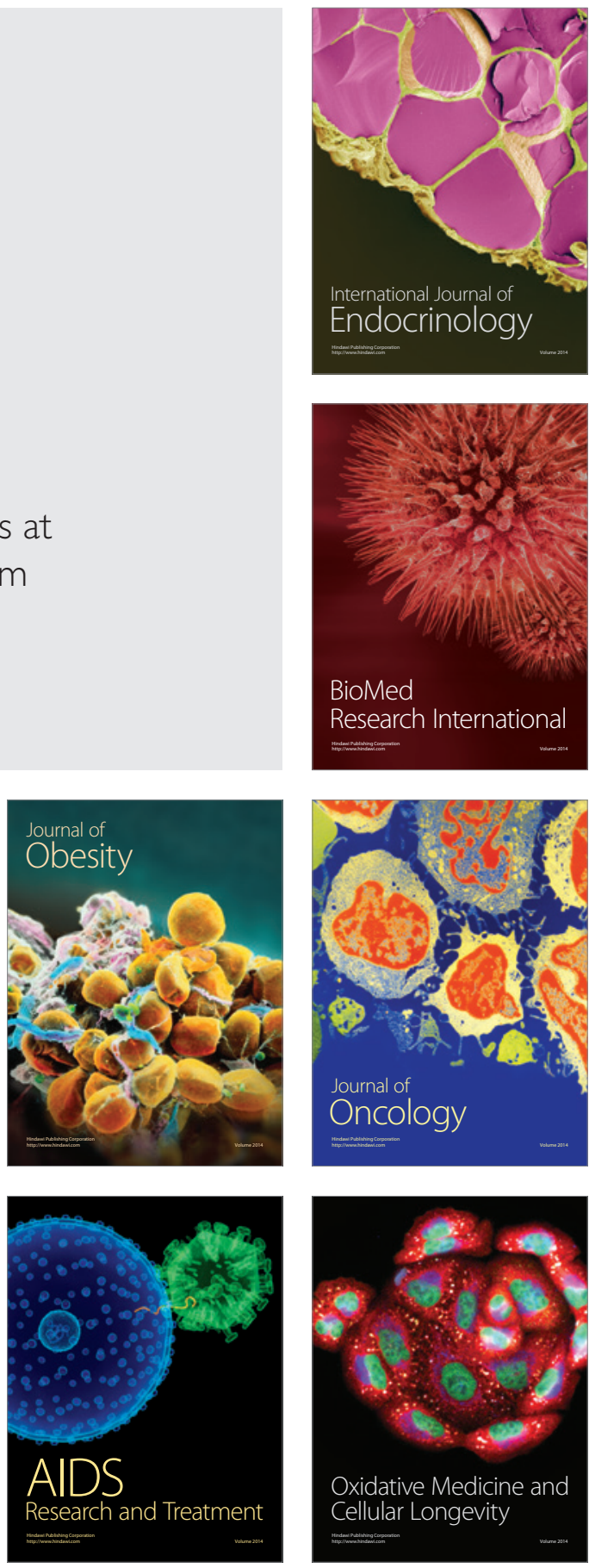